\title{
Diyarbakır İstasyonunda 1929-2016 Boyunca Tarihsel Kuraklığın Yenilikçi Şen Yöntemi ile Trend Analizi
}

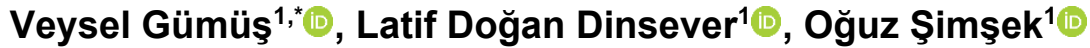 \\ ${ }^{1}$ Harran Üniversitesi, Mühendislik Fakültesi, Inşaat Mühendisliği Bölümü, 63050, Şanlıurfa. \\ Özet
}

Bir doğal afet olarak kuraklık; su temini, hidroelektrik üretimi, tarım ve sanayi gibi çeşitli sektörleri etkilemektedir. Su kaynaklarının etkin ve verimli kullanılması açısından, kuraklığın zamansal değişiminin belirlenmesi önem arz etmektedir. Bu çalışmada, Diyarbakır ilindeki meteoroloji gözlem istasyonunda 1929-2016 yılları arasında ölçülmüş aylık toplam yağlş verileri kullanılarak kuraklık analizi yapılmıştır. Kuraklık analizinden önce verilerin homojenliği kontrol edilmiştir. Kuraklığın belirlenmesinde, Standartlaştırılmış Yağış Indeksi (SYİ) yöntemi kullanılmış ve 1, 3, 6 ve 12 aylık zaman ölçeklerinde meydana gelen tarihsel kuraklık indis değerleri belirlenmiştir. Farklı zaman ölçeklerine göre hesaplanan kuraklık indis değerlerinin trendini belirlemek için Yenilikçi Şen Yöntemi (Innovative Trend Analysis-ITA) kullanılmıştır. Çalışmada, 1, 3, 6 ve 12 aylık zaman ölçekleri için en kurak periyodlar sırasıyla 8, 18, 21 ve 53 ay olarak belirlenmiştir. 1 aylık zaman ölçeğinde (SYI-1) kurak dönem meydana gelme oranı \%40 iken, diğer zaman ölçeklerinde bu değerin yaklaşı \%50 olduğu, ayrıca üç aylık (SYİ-3), altı aylık (SYİ-6) ve 12 aylık (SYİ-12) için orta kurak ve üzeri kuraklı meydana gelme oranının \%15-16.5 arasında değiştiği görülmüştür. Yenilikçi Şen Yöntemi ile kuraklık indislerinin trendi incelendiğinde ise, özellikle SYI-12 için 0.8'den büyük indis değerlerinde zaylf bir azalma eğilimi, orta nemli sinıfa giren indis değerlerinde ise \%5 üzerinde bir azalma eğilimi belirlenmiştir. Ayrıca, SYİ-12 değerlerinde -3 ve -3'ten küçük indis değerlerinin güçlü bir artış (\%10 ve üzeri) eğilimi gösterdiği, yani aşırı kurak durumun son yıllarda azaldığı tespit edilmiştir.

\section{Anahtar Sözcükler}

Kuraklık Analizi, Trend Analizi, Homojenlik, Standartlaştırılmış Yağış İndeksi, Yenilikçi Şen Yöntemi

\section{Trend Analysis of Historical Drought During 1929-2016 in Diyarbakır Station with Innovative Şen Method}

\begin{abstract}
Drought, a natural disaster, affects various sectors such as water supply, hydropower generation, agriculture, and industry. It is important to determine temporal change of drought in order to use water resources effectively and efficiently. In this study, drought analysis is performed using monthly total precipitation data measured between 1929-2016 at the meteorology observation station in Diyarbakir, Turkey. A homogeneity test is also made before drought analysis. The Standardized Precipitation Index (SPI) method is used to determine drought for 1, 3, 6 and 12 months' time scales, and Innovative Şen Method (also known as Innovative Trend AnalysisITA) is used to identify the trend of drought indices values for different time scales. The driest periods are determined according to time scales of 1, 3, 6 and 12 months are found as 8, 18,21 and 53 months, respectively. While the percentage of dry periods is $40 \%$ for the 1-month time scale (SPI-1), and about 50\% for the other time scales. The percentage of droughts (sum of moderate, severe, and extreme drought) for 3-months (SPI-3), 6-months (SPI-6) and 12-months (SPI-12) is between 15\% and 16.5\%. The ITA method results show that a weak decreasing trend found on SPI-12 for indices value greater than 0.8, and a strong decreasing trend (more than 5\%) is calculated for moderate wet values. In addition, it is determined that the index values, less than -3 and -3 , in SPI-12 values shows a very strong increasing trend (more than 10\%). Its means that the extreme dry situation has decreased in recent years.
\end{abstract}

Keywords

Drought Analysis, Trend Analysis, Homogeneity, Standardized Precipitation Index, Innovative Şen Method

\section{Giriş}

Kuraklık, toplumun farklı kesimleri ve çevre üzerinde önemli etkileri olan en yıkıcı doğal afetlerden biridir. Ekonomi üzerindeki olumsuz etkilerinin yanı sıra sosyal etkileri de oldukça fazla olan kuraklık, dünyanın hemen hemen tüm iklim bölgelerinde görülmektedir (Wilhite 2000). Kuraklık, meteorolojik, hidrolojik, tarımsal ve sosyoekonomik kuraklık olarak sinıflandırılmaktadır (Heim 2002; Wilhite ve Glantz 1985). Canlılar üzerinde en etkili kuraklık türü olan meteorolojik kuraklık, yağışların uzun dönem ortalama değerlerden az olması, hidrolojik kuraklık; yağışın az olduğu dönemlerde yüzeysel akışta meydana gelen azalma olarak tanımlanır (Liu vd. 2012). Tarımsal kuraklık ise bitkilerin gelişmesi için yeterince nemin toprakta bulunmaması olarak ifade edilir (Botterill 2003).

* Sorumlu Yazar: Tel: +90 (414) 3183000 Faks: +90 (414) 3183190

E-posta: gumus@harran.edu.tr (Gümüş V), latifddinsever@harran.edu.tr (Dinsever LD) oguzsimsek@harran.edu.tr (Şimşek O)
Gönderim Tarihi / Received : 22/02/2021

Kabul Tarihi / Accepted

: 09/07/2021 
Kuraklık farklı değişkenlere bağlı olarak her ne kadar bu şekilde sınıflandırılmış olsa da kuraklık türleri birbirleri ile doğrudan ilişkilidir. Örneğin, yağışın az olması akışı doğrudan etkilemekte olup, toprak nemi ise hem yağış hem de akış ile yine doğrudan ilişkilidir. Diğer kuraklık türlerinin ortaya çıkmasına neden olan meteorolojik kuraklığ 1 belirlemek için farklı yöntemler geliştirilmiştir. Bu yöntemlerin önemli bir kısmı, yağış değerlerini kuraklığın analizinde ana girdi olarak değerlendirmektedir.

Meteorolojik kuraklık indis değerlerinin hesaplanmasında yaygın olarak kullanılan yöntem, Standartlaştırılmış Yağış İndeksi (SYİ)'dir. McKee vd. (1993) tarafından önerilen bu yöntem, aylık toplam yağış verilerini kullanarak indis değeri hesaplamaktadır. Byun ve Wilhite (1999) tarafından geliştirilen Efektif Kuraklık İndisi de (EDI) kuraklığı belirlemek için SYİ yöntemine benzer olarak yağış verilerini kullanmaktadır. Ayrıca, literatürde sıklıkla kullanılan diğer bir yöntem olan Palmer Kuraklık Şiddeti İndisi (PDSI)'de (Palmer 1965) meteorolojik kuraklığın izlenmesinde kullanılmaktadır. Ancak bu indis değeri, girdi parametresi olarak ortalama sıcaklık, toplam yağış ve faydalı su içeriğini girdi olarak kullanmaktadır. Literatür incelendiğinde, Dünya'nın farklı bölgelerinde SYİ yönteminin kuraklık değerlendirmesinde en sık kullanılan yöntem olduğu dikkat çekmektedir. Örneğin, Mishra ve Desai (2005) Hindistan'ın Kansabati nehir havzasındaki 19652001 yılları arasındaki yağış verilerini kullanarak SYİ yöntemi ile meteorolojik kuraklık indislerinin zamansal ve mekânsal değişimlerini belirlemiş ve kuraklığın süre, şiddet ve frekansını da değerlendirerek 1980'li yıllarda ciddi kuraklık yaşandığını tespit etmişlerdir. Keskin vd. (2011), Türkiye'nin Akdeniz Bölgesindeki Göller Bölgesi'nde yer alan 5 istasyona ait ortalama yağış değerleri kullanılarak, SYİ yöntemi ile farklı zaman ölçeklerinde kuraklığ 1 değerlendirmiştir. Omonijo ve Okogbue (2014), Kuzey Nijerya bölgesinde 1907-2006 yılları arasındaki aylık yağış verilerini kullanarak 1, 3, 6 ve 12 aylık olmak üzere SYİ yöntemi ile kuraklık analizi yapmışlar ve bölgede genellikle şiddetli ve periyodu uzun olan kuraklıklar yaşandığını belirlemişlerdir. Nyatuame ve Agodzo (2017), Gana'da bulunan Tordzie havzasındaki istasyonlara ait 1984-2014 yılları arasındaki yağış verilerini kullanarak farklı zaman ölçeklerinde $(3,6,9,12)$ SYİ yöntemi ile zamansal kuraklık analizi yapmış ve bölgenin kuraklık ve sel tehlikelerine açık olduğu sonucunu elde etmişlerdir. Liu vd. (2018), çalışmalarında Quanzhou'da yer alan altı istasyona ait 1960-2014 yılları arasındaki aylık yağış verileri ile SYİ yöntemini kullanarak kurak ve nemli dönemlerin karakteristiğini hesaplamışlardır. Marini vd. (2018), Güney İtalya'da bulunan Apulia bölgesi için 1960-2013 yılları arasındaki yağış verilerini kullanarak, SYİ ve Keşif Kuraklık İndeksi (Reconnaissance Drought Index-RDİ) yöntemleriyle mekânsal ve zamansal kuraklık analizi yapmış ve iki yöntemde de 1985-1995 yılları arasında şiddetli bir kuraklık yaşandığını tespit etmişlerdir. Naz vd. (2020), Pakistan'ın Belucistan eyaletinde bulunan 10 meteoroloji istasyonuna ait 1980-2017 yıllarına arasındaki aylık yağış verileri ile 3 aylık zaman ölçeğinde SYİ analizi yapmıştır. Liu vd. (2021), Güneybatı Çin'de yer alan Sichuan eyaletindeki 44 meteoroloji istasyonuna ait 1961-2019 yıllarındaki verileri kullanarak, SYİ ve Standartlaştırılmış Yağış Evapotranspirasyon İndeksi (SYEİ) yöntemleri ile zamansal ve mekânsal kuraklık analizi uygulamışlardır.

Kuraklığın belirlenmesinin yanında kuraklığın trendinin belirlenmesi de kuraklığa karşı etkin mücadele edilmesinin ve su kaynaklarının gelecek planlanmasın yapılmasında önemlidir. Belirlenen tarihsel kuraklıklar bölgenin kuraklık ile ilgili davranışı hakkında önemli bilgiler vermektedir. Tarihsel kuraklıkların zamansal değişiminin belirlemek için trend analizi başvurulan önemli yöntemlerden biridir (Andreadis ve Lettenmaier 2006). Mann-Kendall testi (Kendall 1948; Mann 1945) yaygın uygulanan parametrik olmayan trend analizi yöntemidir (Jamro vd. 2020; Naz vd. 2020; Sharafati vd. 2020; Vicente-Serrano vd. 2020). Ancak, bu test zaman serisinde zamansal kuraklık indis değerlerinin monotonik trendlerini belirlemektedir. Son yıllarda geleneksel Mann-Kendall testinin yanı sıra, sonuçları grafiksel olarak yorumlama yeteneği olan ve kuraklık sınıfı gibi belli değer aralıklarının değişimlerini değerlendirmeyi sağlayan Yenilikçi Şen Yöntemi'nin (Innovative Şen Method-ITA) (Şen 2012) hidro-meteorolojik verilerin trendinin belirlenmesinde kullanımı artmıştır. Örneğin, Cui vd. (2017), 1960-2015 yılları arasında Çin'in Yangtze Nehri Havzası'nda hava sıcaklığı ve yağış değişimlerini doğrusal regresyon analizi, Mann-Kendall ve ITA yöntemi ile incelemişlerdir. Çalışmalarının sonucunda, 1960-2015 döneminde tüm çalışma alanında yıllık maksimum, minimum ve ortalama sıcaklığın önemli ölçüde arttığını göstermişlerdir. Tosunoglu ve Kisi (2017), Çoruh Havzası'nda bulunan 9 adet istasyondan elde edilen günlük akış kayıtlarını kullanarak Mann-Kendall, Modifiye Edilmiş Mann-Kendall ve ITA yöntemlerini uygulayarak maksimum hidrolojik kuraklık değişkenleri, yıllık maksimum süre ve yıllık maksimum şiddet eğilimlerini araştırmışlardır. Çalışmada, Mann-Kendall yöntemi ile anlamlı trend belirlenemezken, Modifiye Edilmiş Mann-Kendall ve ITA yöntemleri ile farklı istasyonlarda kuraklık şiddeti ve süresi için anlamlı trend belirlenmiştir. Caloiero (2018), farklı zaman ölçeklerinde (3, 6, 12, 24 aylık) SYİ yöntemi ile Yeni Zelanda'daki kuru ve islak dönemleri belirlemiş ve ardından elde ettiği değerlerin trendini düşük, orta ve yüksek değer için ITA yöntemi ile tespit etmiştir. Trend analizi sonucunda, indis değerlerinin eğilimde genel bir azalma olduğunu yani daha şiddetli kuraklıklara ve daha az yağışa yönelik bir eğilim olduğunu belirlemiştir. Nourani vd. (2018), Kuzey-Batı İran'da yer alan Urmia Göl havzasında 1971-2013 yılları arasındaki yağış, akarsu akışı, sıcaklık ve nem miktarlarındaki eğilimleri aylık, mevsimsel ve yıllık olarak araştırmışlardır. Eğilimlerin belirlenmesinde Mann-Kendall yöntemi ve Yenilikçi Şen yöntemi kullanılmış ve su seviyesi ve akış serilerinde önemli ölçüde düşüş belirlenirken, yağış ve bağıl nem serilerinde orta derecede azalma ve gözlemlenen sıcaklık verilerinde artış eğilimleri tespit edilmiştir. Literatürde, farklı zaman serileri için yapılan analizlerde, monotonik trend belirleyen yöntemlerin yanı sıra, belirli bir veri aralığının artış ya da azalma eğiliminde olup olmadığının belirlenebilmesi için ITA yöntemi sıklıkla kullanıldığ 1 görülmektedir. Geçmişte yapılmış çalışmalar incelendiğinde, ITA yöntemi ile sadece kuraklık indis değerlerinde değil, kuraklığın şiddetini belirleyen indis değer aralıklarında da değişimin belirlenmesine imkân tanıması nedeniyle bu yöntem özellikle tercih edilmiştir. 
Bu çalışma kapsamında, 1929-2016 yılları arasında Diyarbakır il merkezinde bulunan meteoroloji istasyonuna ait meteorolojik kuraklık, aylık toplam yağış verileri kullanılarak farklı zaman ölçeklerinde SYİ yöntemi ile hesaplanmıştır. Toplam dört zaman ölçeği için $(1,3,6,12$ aylık) hesaplanan kuraklıkların süresi, şiddeti, yoğunluğu ve tepe noktaları belirlenerek tarihsel kuraklıklar değerlendirilmiştir. Hesaplanan tarihsel kuraklıkların trendleri, her bir kuraklık sınıfındaki değişimlerin detaylı değerlendirilmesi için Yenilikçi Şen Yöntemi ile incelenmiş ve Diyarbakır ilindeki kuraklıkların değişimi farklı zaman ölçeklerinde detaylı bir şekilde analiz edilmiştir.

\section{2. Çalışma Alanı}

Bu çalışma kapsamında, Diyarbakır ilinde bulunan (Şekil 1) 17280 numaralı istasyona ait (37.8973 K, 40.2027 D) aylık toplam yağış verileri kullanılmıştır. Bu istasyonda kaydedilen yağış verilerine ait aylık ortalama (Ort), minimum (Min), maksimum (Max), standart sapma (Std. Sapma) ve çarpıklık değerleri Tablo 1'de verilmektedir. Bu istatistiklere göre en az yağış temmuz, ağustos ve eylül aylarında meydana gelirken, en fazla yağış ise beklenildiği gibi aralık ve ocak aylarında meydana gelmiştir. Ayrıca, yağışın az olduğu dönemler olan temmuz, ağustos ve eylül aylarında standart sapma nispeten düşük belirlenirken, en fazla çarpıklık ise eylül ayında meydana gelmiştir.

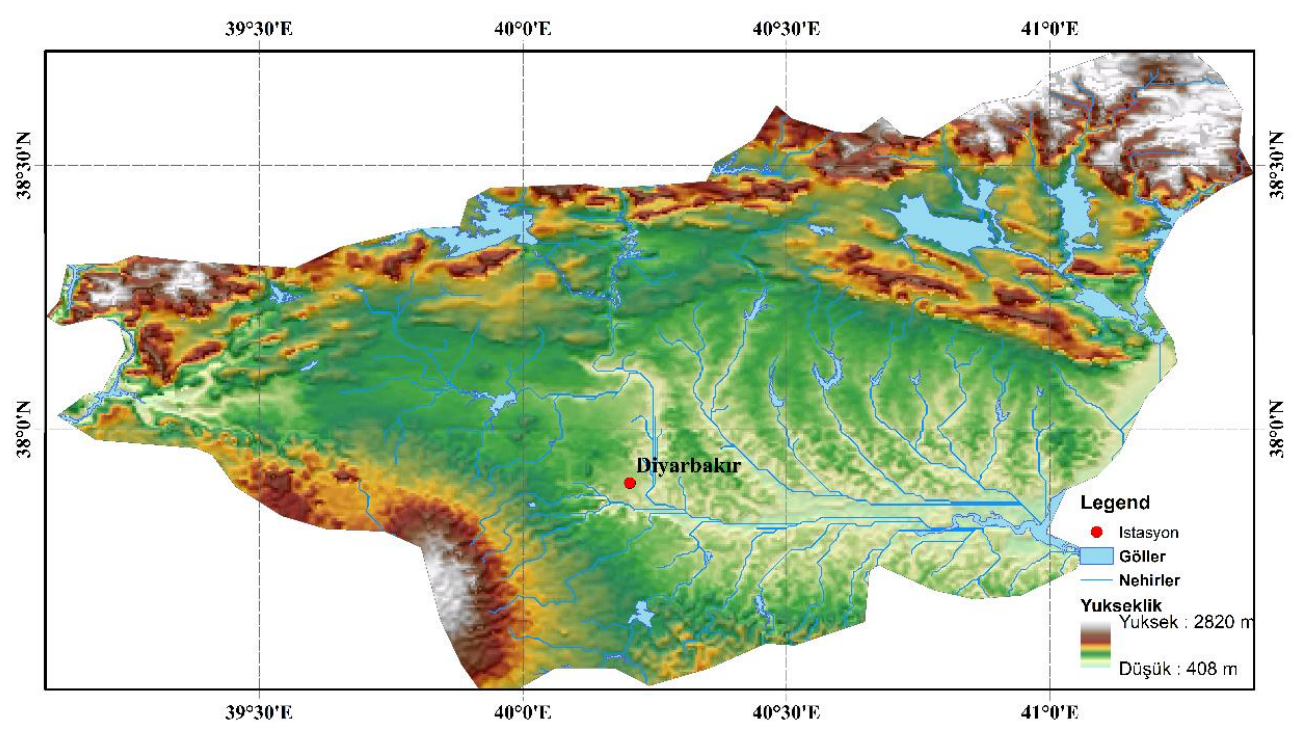

Şekil 1: Çalışma alanı

Tablo 1: Diyarbakır istasyonu toplam yağış verilerinin istatistiksel parametreleri

\begin{tabular}{cccccccccccccc}
\hline Parametre & \multirow{2}{*}{ Ocak } & Şubat & Mart & Nisan & Mayıs & Haziran & Temmuz & A ğustos & Eylül & Ekim & Kasım & Aralık & $\begin{array}{c}\text { Yıllık } \\
\text { Toplam }\end{array}$ \\
\hline Ort & 71.81 & 68.80 & 65.27 & 68.92 & 42.46 & 8.69 & 0.85 & 0.53 & 4.51 & 32.86 & 55.55 & 71.89 & 492.14 \\
Min & 0.70 & 12.70 & 1.50 & 1.80 & 0.00 & 0.00 & 0.00 & 0.00 & 0.00 & 0.00 & 1.00 & 0.00 & 206.20 \\
Max & 188.90 & 151.80 & 210.30 & 209.00 & 182.20 & 47.80 & 7.40 & 9.50 & 68.20 & 148.10 & 175.30 & 237.00 & 775.40 \\
Std. Sapma & 37.75 & 33.14 & 37.38 & 44.17 & 40.83 & 9.97 & 1.66 & 1.44 & 9.47 & 32.60 & 31.70 & 43.82 & 116.11 \\
Çarpıklık & 0.55 & 0.46 & 0.91 & 0.88 & 1.37 & 1.54 & 2.63 & 3.89 & 4.43 & 1.12 & 0.84 & 1.03 & 0.13 \\
\hline
\end{tabular}

\section{Yöntem}

\subsection{Standartlaştırılmış Yağış İndeksi (SYi)}

Yağış verileri kullanılarak bir istasyonda meydana gelen tarihsel kuraklıkları belirlemek için McKee vd. (1993) tarafından önerilmiş ve ülkemizde ve dünyada sıklıkla tercih edilmekte olan Standartlaştırılmış Yağış İndeksi (SYİ) yöntemi kullanılmıştır (Dashtpagerdi vd. 2015; Nazmi vd. 2016; Gumus ve Algin 2017; Dikici 2020). Bu yöntem ile SYİ değerleri, kümülatif yağış verilerini gama olasılık yoğunluk fonksiyonuna uydurma işlemi sonrasında, Denklem 1'deki gibi hesaplanmaktadır.

$$
S Y \dot{I}=\frac{P_{i j}-P_{i m}}{\sigma_{p}}
$$


Burada; $P_{i j}, i$. yağış istasyonundaki $j$. gözlemdeki aylık yağışı, gözlemdeki aylık yağışı; $P_{i m}, \mathrm{P}_{i}$ istasyonuna ait aynı ayın uzun dönemli yağış ortalamasını ve $\sigma_{p}$ standart sapmayı ifade etmektedir. Standartlaştırılarak boyutsuzlaştırılan SYI değerinin; negatif olması kurak, pozitif olması ise nemli olarak ifade edilir. SYİ değerlerinin ardışık olarak negatif olması ise kurak dönem olarak tanımlanır. SYİ metodunda, aylık yağış veri setleri en az 30 yıllık kesintisiz dönem için düzenlenir ve SYİ yöntemi ile kuraklık şiddeti Tablo 2'de gösterilen kategorilere göre sınıflandırılabilir (Gumus ve Algin, 2017; McKee vd. 1993; Vermes 1998).

Tablo 2: SYI değerlerinin sınıflandırılması (Gumus ve Algin 2017)

\begin{tabular}{|c|c|}
\hline SYİ Değerleri & Kuraklık Sınıflandırılması \\
\hline SYI $>2.0$ & Aşırı Nemli (AN) \\
\hline $1.5<\mathrm{SY} \dot{\mathrm{I}} \leq 2.0$ & Çok Nemli (ÇN) \\
\hline $1.0<\mathrm{SY} \dot{\mathrm{I}} \leq 1.5$ & Orta Nemli (ON) \\
\hline $0<\mathrm{SY} \leq 1.0$ & Hafif Nemli $(\mathrm{HN})$ \\
\hline$-1.0<\mathrm{SY} \dot{\mathrm{I}} \leq 0$ & Hafif Kurak $(\mathrm{HK})$ \\
\hline$-1.5<\mathrm{SY} \dot{\mathrm{I}} \leq-1.0$ & Orta Kurak $(\mathrm{OK})$ \\
\hline$-2.0<\mathrm{SYI} \leq-1.5$ & Çok Kurak (ÇK) \\
\hline$-2.0 \geq \mathrm{SY} \dot{\mathrm{I}}$ & Aşırı Kurak (AK) \\
\hline
\end{tabular}

\subsection{Yenilikçi Şen Yöntemi (Innovative Trend Analysis-ITA)}

Şen (2012) tarafından önerilen bu yöntemde, ölçümü alınan hidrolojik değişkenin veri serisi, zamansal olarak ölçüm başlangıç tarihinden son ölçüm tarihine doğru sıralanır. Sonrasında, oluşan seri ilk tarihten itibaren iki eşit parçaya ayrılır ve ayrı ayrı kendi içinde küçükten büyüğe doğru sıralanır. Kartezyen koordinat sistemine göre, oluşan iki veri sütununun ilki (y1) X-eksenine, diğeri (y2) ise Y-eksenine yerleştirilir (Şekil 2).

Oluşan iki boyutlu grafik üzerinde veri noktaları 1:1 $\left(45^{\circ}\right)$ çizgisinin üzerine toplanmış ise bu veri setinde bir trend yoktur, çizginin altında ise azalan, üstünde olması durumunda ise artan bir trend olduğu şeklinde yorumlanmaktadır. Ancak, trend varlığını daha nicel olarak belirleyebilmek için Tosunoglu ve Kisi (2017) tarafından önerilen 1:1 çizgisine paralel ve veri setine $\pm \% 5$ ve $\pm \% 10$ mesafede çizgiler oluşturularak trend varlığ $1: 1$ ile $\pm \% 5$ arasında olması durumu "trend var" , $\pm \% 5-\% 10$ arasında olması durumu "güçlü trend var", $\pm \% 10$ çizgisinin üzerinde olması durumu ise "çok güçlü trend var" şeklinde değerlendirilmiştir. ITA yönteminin diğer yöntemlere göre en güçlü yanı, sadece trend var ya da trend yok gibi bir tespit yapmasının yanında, trendin hangi verilerde olduğunu da göstermesidir (Şen 2012; Tosunoglu ve Kisi 2017).

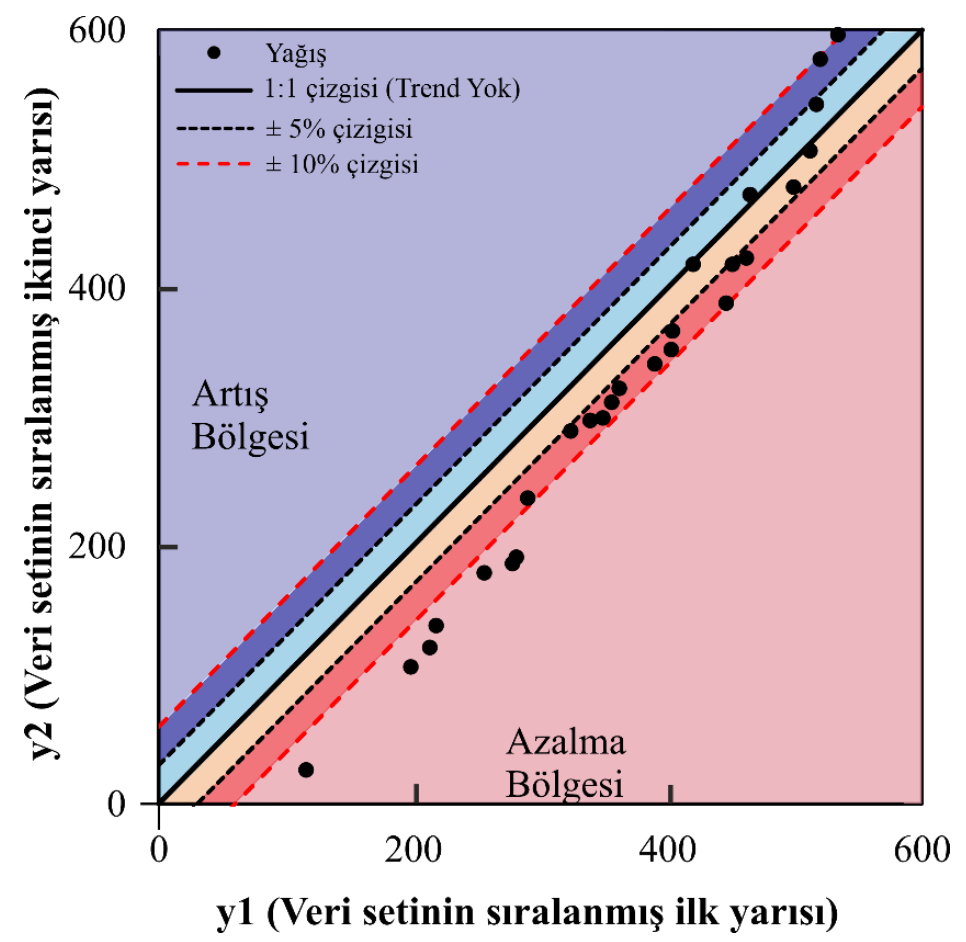

Şekil 2: Şen (2012)'ye göre trend meydana gelme durumu 


\section{Bulgular}

\subsection{Homojenlik Analizi}

17280 numaralı Diyarbakır istasyonuna ait 1929-2016 yılları arasındaki aylık toplam yağış verilerinin homojenliğinin belirlenmesi için Pettitt (Pettitt 1979), Standart Normal Homojenlik Testi (SNHT) (Alexandersson ve Moberg 1997), Buishand (Buishand 1982) yöntemleri kullanılmış ve bu yöntemler kullanılarak elde edilen homojenlik sonuçları Tablo 3'te verilmiştir. Tablo 3'e göre, Pettitt testinde sadece haziran ayında, SNHT ve Buishand yönteminde ise sadece eylül ayı verilerinin alfa $=0.05$ yanılma olasılığı için homojen olmadıkları belirlenmiştir. Tüm testlerde ortak bir homojen olmayan durumun oluşmaması, homojen olmayan ayların çoğunlukla yağışın düzenli meydana gelmediği aylarda (haziran ve eylül) oldukları, ayrıca yıllık toplam yağışların tüm testlerde homojen olması nedeniyle veriler güvenli olarak değerlendirilmiş ve kuraklık analizi bu veriler üzerinden gerçekleştirilmiştir.

Tablo 3: Kullanılan verilerin farklı homojenlik testlerine ait sonuçları

\begin{tabular}{|l|c|c|c|c|c|c|c|c|c|}
\hline \multirow{2}{*}{ Aylar } & \multicolumn{3}{|c|}{ Pettitt } & \multicolumn{3}{c|}{ SNHT } & \multicolumn{3}{c|}{ Buishand Q } \\
\cline { 2 - 11 } & K & $\mathbf{t}$ & $\mathbf{p ~ d e g ̆ e r i ~}$ & $\mathbf{T}_{\mathbf{0}}$ & $\mathbf{t}$ & $\mathbf{p ~ d e g ̆ e r i}$ & $\mathbf{Q}$ & $\mathbf{t}$ & p değeri \\
\hline Ocak & 388 & 41 & 0.442 & 3.606 & 41 & 0.568 & 8.938 & 41 & 0.256 \\
\hline Şubat & 185 & 46 & 0.991 & 1.765 & 8 & 0.955 & 3.783 & 46 & 0.986 \\
\hline Mart & 519 & 12 & 0.147 & 8.343 & 10 & 0.095 & 9.121 & 12 & 0.234 \\
\hline Nisan & 464 & 54 & 0.236 & 3.594 & 54 & 0.584 & 8.708 & 54 & 0.288 \\
\hline Mayıs & 356 & 62 & 0.545 & 2.024 & 15 & 0.898 & 5.252 & 17 & 0.861 \\
\hline Haziran & 627 & 74 & 0.044 & 10.330 & 74 & 0.066 & 11.091 & 74 & 0.093 \\
\hline Temmuz & 442 & 42 & 0.213 & 6.784 & 26 & 0.248 & 11.212 & 26 & 0.076 \\
\hline Ağustos & 267 & 17 & 0.635 & 2.493 & 65 & 0.726 & 6.545 & 65 & 0.619 \\
\hline Eylül & 523 & 66 & 0.135 & 20.643 & 78 & 0.039 & 14.454 & 66 & 0.002 \\
\hline Ekim & 337 & 55 & 0.618 & 3.409 & 58 & 0.617 & 8.257 & 58 & 0.350 \\
\hline Kasım & 321 & 50 & 0.676 & 4.029 & 6 & 0.504 & 4.773 & 6 & 0.910 \\
\hline Aralık & 324 & 19 & 0.668 & 4.987 & 4 & 0.343 & 7.178 & 19 & 0.517 \\
\hline Yillık Toplam & 382 & 13 & 0.470 & 7.395 & 4 & 0.109 & 7.449 & 13 & 0.475 \\
\hline
\end{tabular}

\subsection{Kuraklık Analizi}

SYİ yöntemi ile 1929-2016 yılları arasında hesaplanan 1, 3, 6 ve 12 aylık indis değerleri Şekil 3'te verilmiştir. Şekil 3'e göre, SYİ-1 değerlerinde en uzun kuraklık iki farklı zaman periyodunda oluşmuş ve 8 ay olarak sürmüştür. Bu periyotların başlangıç tarihleri sırasıyla Eylül 1960 ile Kasım 1969 olduğu görülmüştür. Ayrıca, SYİ-1 (1 aylık indis) için en yüksek kurak değer Ocak 1989 yılında -4.16 olarak belirlenmiştir. Üç aylık yağış verilerinin toplamından elde edilen zaman serisi ile hesaplanan SYİ-3 (3 aylık indis) için en uzun iki kurak dönem 16 ve 18 ay sürmüş ve bunlar sırasıyla Ekim 1969 ile Temmuz 1972 tarihlerinde başlamıştır ve bu zaman periyodunda en yüksek kuraklık indis değeri ise Nisan 1989 'da -3.2 olarak belirlenmiştir. Bu iki zaman periyodunda elde edilen indis değerleri karşılaştırıldığında, SYİ-3 zaman periyodunda kurak dönem devam etme süresi net bir şekilde artış göstermiştir. SYİ-6 (6 aylık indis) için ise ardışık kurak devam eden ay sayısı artış miktarı SYİ 3'e göre sınırlı olmuş ve Temmuz 1959 tarihinde başlayarak 21 ay sürmüştür. SYİ-12 (12 aylık indis) değerleri incelendiğinde ise, iki farklı dönemde meydana gelen kuraklıkların dikkat çekici olduğu görülmüş, en fazla ardışık kurak dönem Ocak 1929 da başlayıp 53 ay sürerken, Mayıs 1988 yılında başlayan kurak dönem ise 32 ay sürmüştür. SYİ-6 ve SYİ-12 için en düşük indis değerleri sırasıyla -2.89 ile Nisan 1929 da, -3.09 ile Şubat 1970 tarihinde meydana gelmiştir. Özellikle 3, 6 ve 12 aylık SYİ değerlerinde pik kurak değerinin düşmesi ve tarihinin değişmesi, kümülatif toplanan yağış verilerinin pik değeri düşürdüğü, yani anlık bir yağış eksikliğinin sürekli olarak devam etmediği anlamına gelmektedir. 

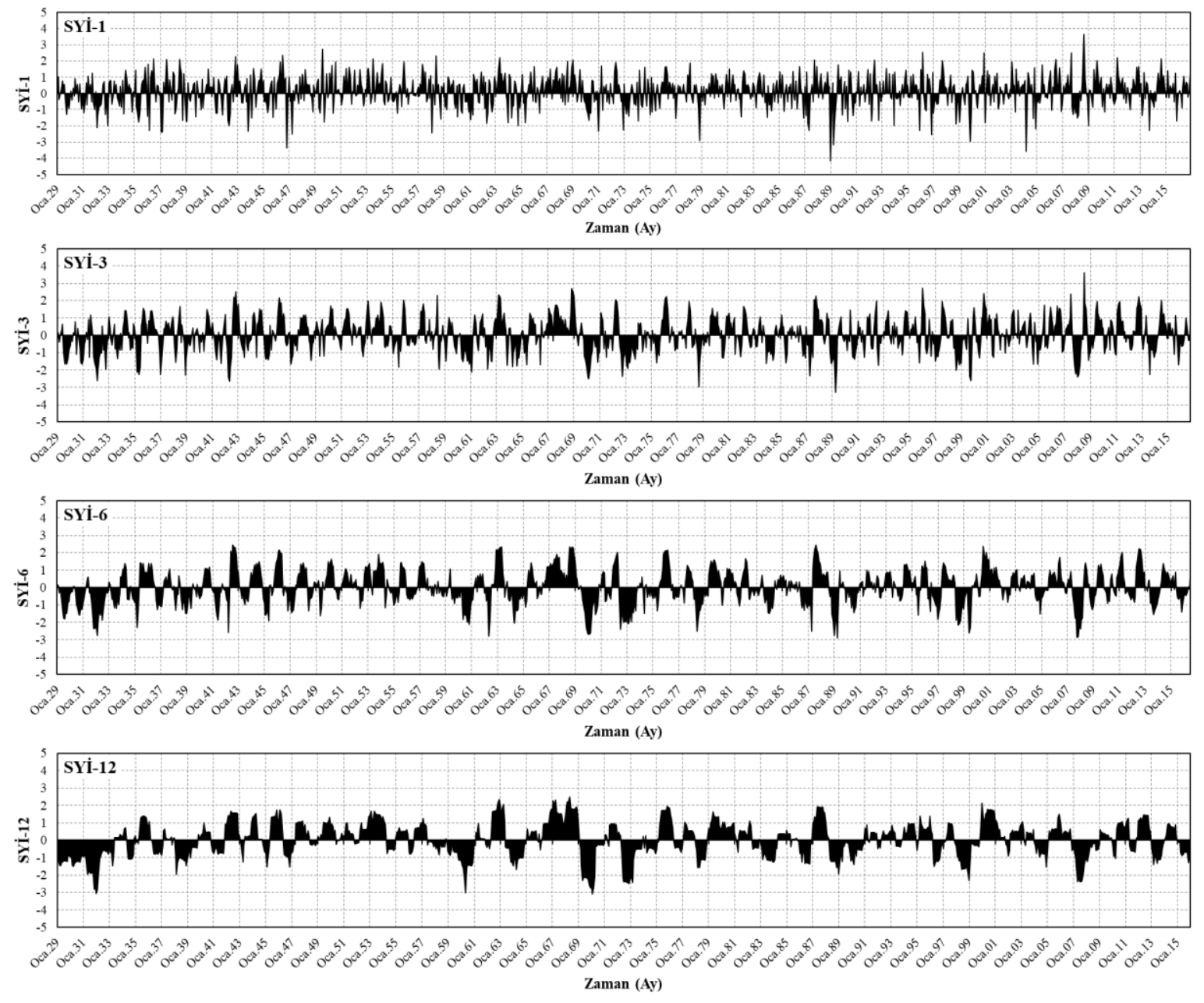

Şekil 3: SYI-1, SYI-3, SYI-6 ve SYI-12 değerlerinin zamansal dağılımları

Şekil 4'te, dört farklı zaman ölçeğine göre hesaplanan indis değerlerinin kurak/nemli olarak meydana gelme oranları verilmiştir. Buna göre, SYİ-1'de nemli dönem meydana gelme oranı \%60 iken, diğer zaman ölçeklerinde bu değer yaklaşık \%50 olarak meydana gelmiştir.

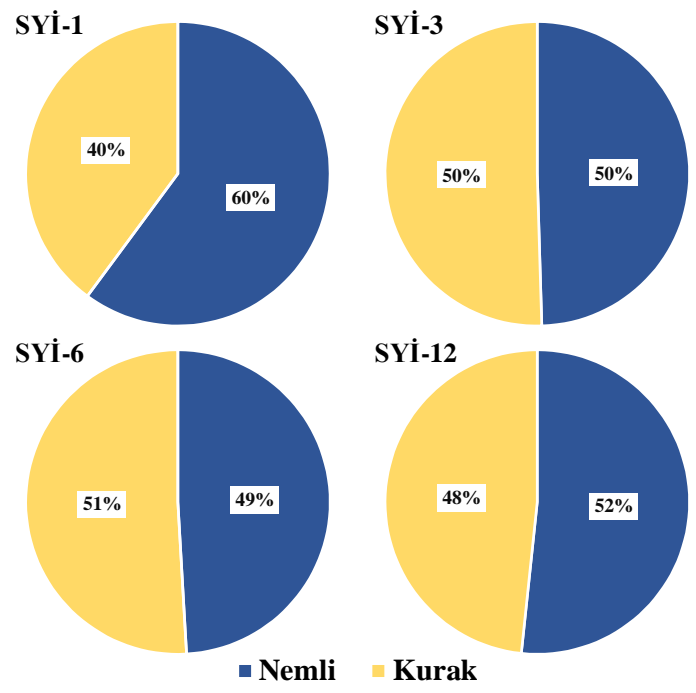

Şekil 4: Farklı zaman ölçeklerine göre nemli/kurak dönem oluşma yüzdeleri 
SYİ-1, SYİ-3, SYİ-6 ve SYİ-12 değerlerinin Tablo 2'de verilen kuraklık sınıflarına göre meydana gelme yüzdeleri, Şekil 5 'te görülmektedir. Buna göre, SYİ-1'de en yüksek hafif yağışılı ve orta nemli durum meydana gelirken, hafif kurak ve orta kurak oluşma yüzdesinde ise en düşük değer yine bu indis değerinde olmuştur. Şekil 4'te, SYİ 1'de yüksek oranda meydana gelen nemli dönemin de çoğunlukla hafif kurak olduğu değerlendirilmektedir. Ayrıca, Şekil 5 'te en yüksek orta kurak (\%10.43) ve aşırı kurak (\%3.25) meydana gelme oranları SYİ-12'de olurken, en düşük aşırı yağış (\%0.86) yine SYİ-12'de meydana gelmiş ve SYİ-12'de orta kurak ve üzeri kuraklık meydana gelme oranı ise \%16.5 olarak hesaplanmıştır. SYİ-3 ve SYİ-6 ise çok nemli hariç tüm sınıflandırmalarda birbirlerine benzer bir oranda çıkmış, orta kurak ve üzeri kuraklık olma durumunun meydana gelme oranı ise \%15 civarında olmuştur. Kuraklık değerlendirilmesinde tarihsel kuraklıkların ele alınması, geçmiş dönemlerde kurak ve nemli dönemlerin daha iyi anlaşılması ve su kaynaklarının planlanması açısından önemlidir. Ancak, tarihsel kuraklıkların zamansal değişimlerinin bilinmesi ve böylece kuraklığın değişim yönünün belirlenebilmesi bu planlama aşamasının daha rasyonel olmasını sağlamaktadır. Bu nedenle, bir sonraki bölümde kuraklığın zamansal değişimi değerlendirilecektir.

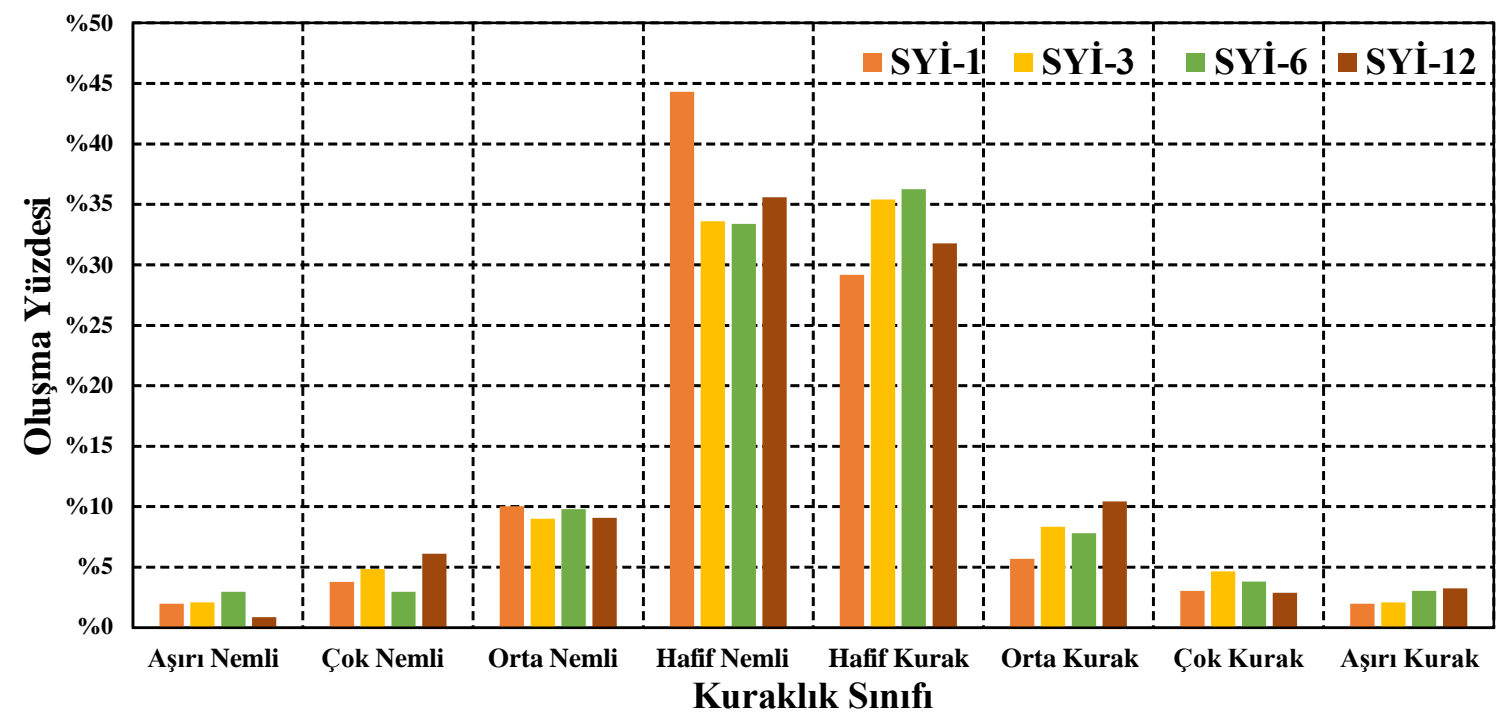

Şekil 5: SYí değerlerinin kuraklık sınıflarına göre oluşma yüzdeleri

\subsection{Trend Analizi}

Bir zaman serisinin monotonik trendi, değişimin sadece yönünü ve istatistiksel olarak anlamlı olup olmadığını vermektedir (Gumus 2019). Ancak, Yenilikçi Şen Yöntemi (Innovative Şen Method-ITA) ise belli bir değer aralığının değişimini grafiksel olarak vermesi nedeniyle değerlendiricilere önemli yorumlama kolaylığı sağlamaktadır. SYİ-1, SYİ3, SYİ-6 ve SYİ-12 değerlerinin ITA yöntemine göre trend analizi sonuçları sirasıyla Şekil 6, Şekil 7, Şekil 8 ve Şekil 9'da verilmiştir. Bu şekillerde verilerin kesikli iki siyah çizgi arasında kalması trendin olmaması, kesikli siyah çizgi ile kesikli kırmızı çizgi arasında olmaları \%5'ten fazla bir değişimin olduğu (değer kesikli siyah çizginin altında ise azalan, tersi durumda ise artan), kesikli kırmızı çizgiyi taşması durumunda ise \%10'dan fazla bir değişim meydana geldiği sonucu ortaya çıkmaktadır. Şekil 6'da verilen SYİ-1 sonuçlarına göre, aşırı nemli, çok nemli, orta nemli ve hafif nemli durumlarda anlamlı bir değişimin olmadığı görülmüştür. SYİ-1 değerlerine göre, kurak dönemler incelendiğinde ise nemli dönemlere benzer bir şekilde hafif kurak, orta kurak ve çok kurak sınıflandırmalarına sahip indislerde bir değişim gözlenmezken, aşırı kurak indislerde bir azalma meydana geldiği görülmektedir. Bu da özellikle ilgili istasyonda aşırı kuraklığın güçlü bir artış eğiliminde olduğunu ifade etmektedir. 

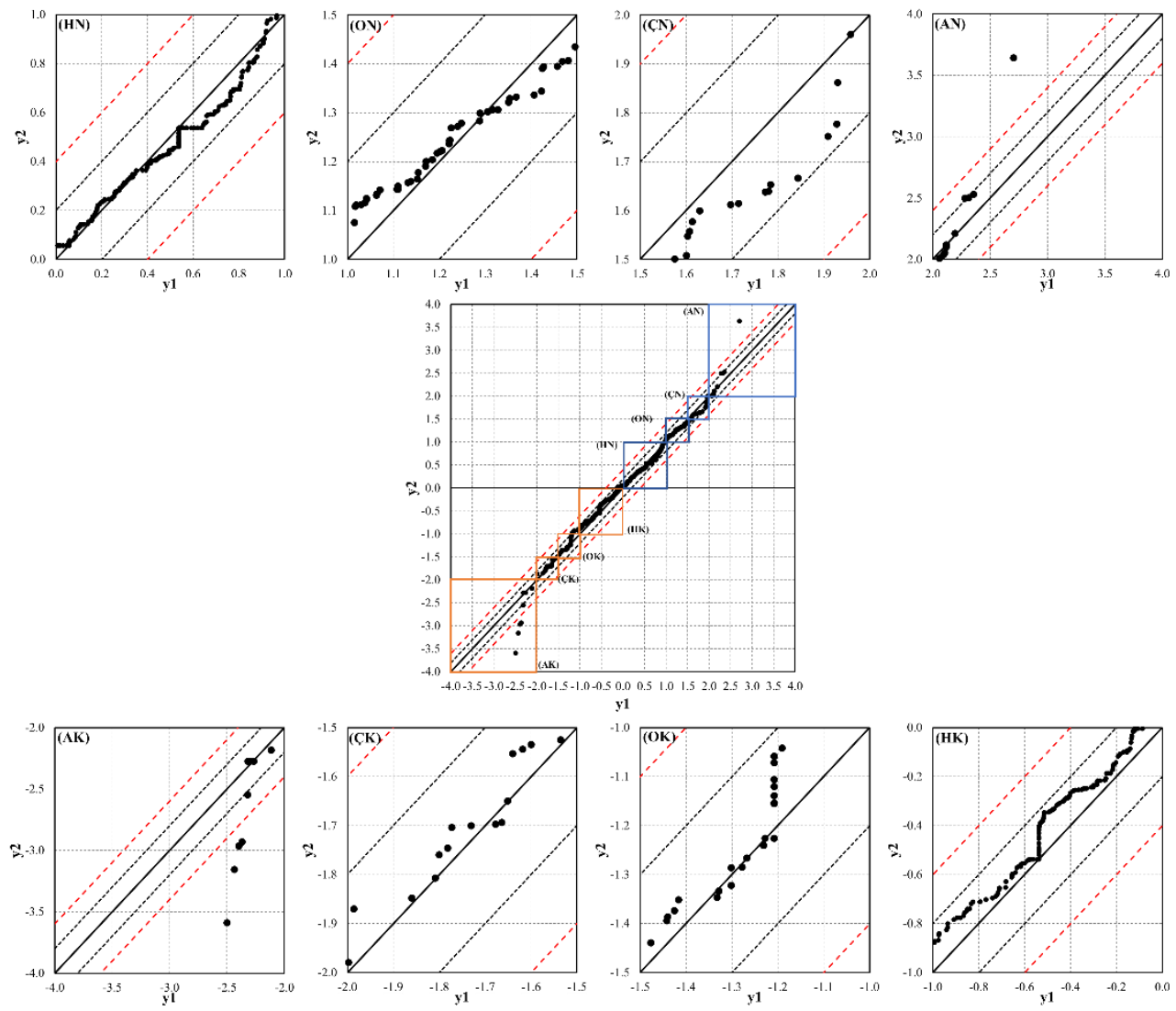

Şekil 6: ITA yöntemine göre SYI 1 değerlerinin değişimleri

ITA yöntemi ile SYİ-3 değerleri için yapılmış olan trend analizi sonuçlar Şekil 7'de verilmiştir. Buna göre, nemli dönemlerin neredeyse 1:1 çizgisi üzerinde yer aldıkları ve herhangi bir değişimin gözlemlenmediği anlaşılmaktadır. Kurak dönemler için ise hafif kurak indis değerlerinin değişim göstermediği, orta ve çok kurak indis değerlerinin çok az da olsa bir artış eğiliminde oldukları görülmektedir. Aşırı kurak indis değerlerinin ise SYİ-1'e benzer ama daha az sayıda bir azalma eğiliminin olduğu belirlenmiştir. Ayrıca, SYİ-1 ve SYİ-3'te AY durumlar için \%10 üzerinde artış ve SYİ 6'da AK durum için ise tek bir değerde \%10 üzerinde azalma eğilimi gösterdiği görülmüştür. Tek bir değerde meydana gelen bu değişimlerin ilgili kuraklık sınıflandırması için bir artma ya da azalma olarak söylenemeyeceği değerlendirilmektedir.

Şekil 8'de verilmiş olan SYİ-6 için yapılan analiz sonucunda sadece aşırı nemli, çok nemli ve orta nemli indis değerlerinde zayıf bir azalma eğilimi gözlenmiş, en fazla veri sayısına sahip hafif nemli indis değerlerinde ve kurak indis değerlerinde herhangi bir değişim gözlemlenmemiştir. Şekil 9'da verilmiş olan SYİ-12 değerlerinin değişimi incelendiğinde, hafif nemli dönemin 0.8 değerlerinden büyük değerlerinde zayıf bir azalma eğilimi, aynı zamanda orta nemli sınıflandırmadaki indis değerlerinde \%5 üzerinden bir azalma eğilimi belirlenmiştir. SYİ-12'nin kurak dönemleri incelendiğinde ise ilk periyotta hesaplanan -3'ten küçük indis değerlerinin \%10 üzerinde güçlü bir artış eğiliminde olduğu, yani aşırı kurak durumun günümüzde azaldığı, çok kurak indis değerlerinin ise \%5'ün üzerinde ve yine artış sergilediği belirlenmiştir.

Kuraklık yağışın bir fonksiyonu olduğundan, geçmiş çalışmalarda yağışın trendler ile kuraklığın trendleri karşılaştırılmıştır. Örneğin, Çiçek ve Duman (2015) Türkiye'nin tamamına ait yağış verilerinin yıllık ve mevsimlik trendlerini belirlemiştir. Çalışmada Diyarbakır istasyonun yer aldığı Güneydoğu Anadolu Bölgesi'ndeki yağışlarda çoğunlukla bir azalma trendi belirlemişlerdir. Ayrıca, Hadi ve Tombul (2018) Diyarbakır dahil 81 il merkezine ait yağış ve sıcaklıkların trend analizini yapmışlardır. Çalışma sonucunda, Güneydoğu Anadolu Bölgesi’nde sıcaklıkların arttı̆̆ı, yağışların ise azaldığı belirlenmiştir. Bu iki çalışmaya göre, kuraklık indislerinde de bir azalma yani kuraklığın olumsuz bir seyir izlemesi beklenmektedir. Ancak, bu çalışmada ITA yöntemi ile yapılan kuraklık şiddetlerinin trend analizinde negatif indis değerlerinin bir artış eğilimi gösterdiği görülmüştür. Bu nedenle sadece yağışın azalması kuraklık şiddetinin değişiminin yorumlanması için yeterli olmadığı değerlendirilmektedir. 

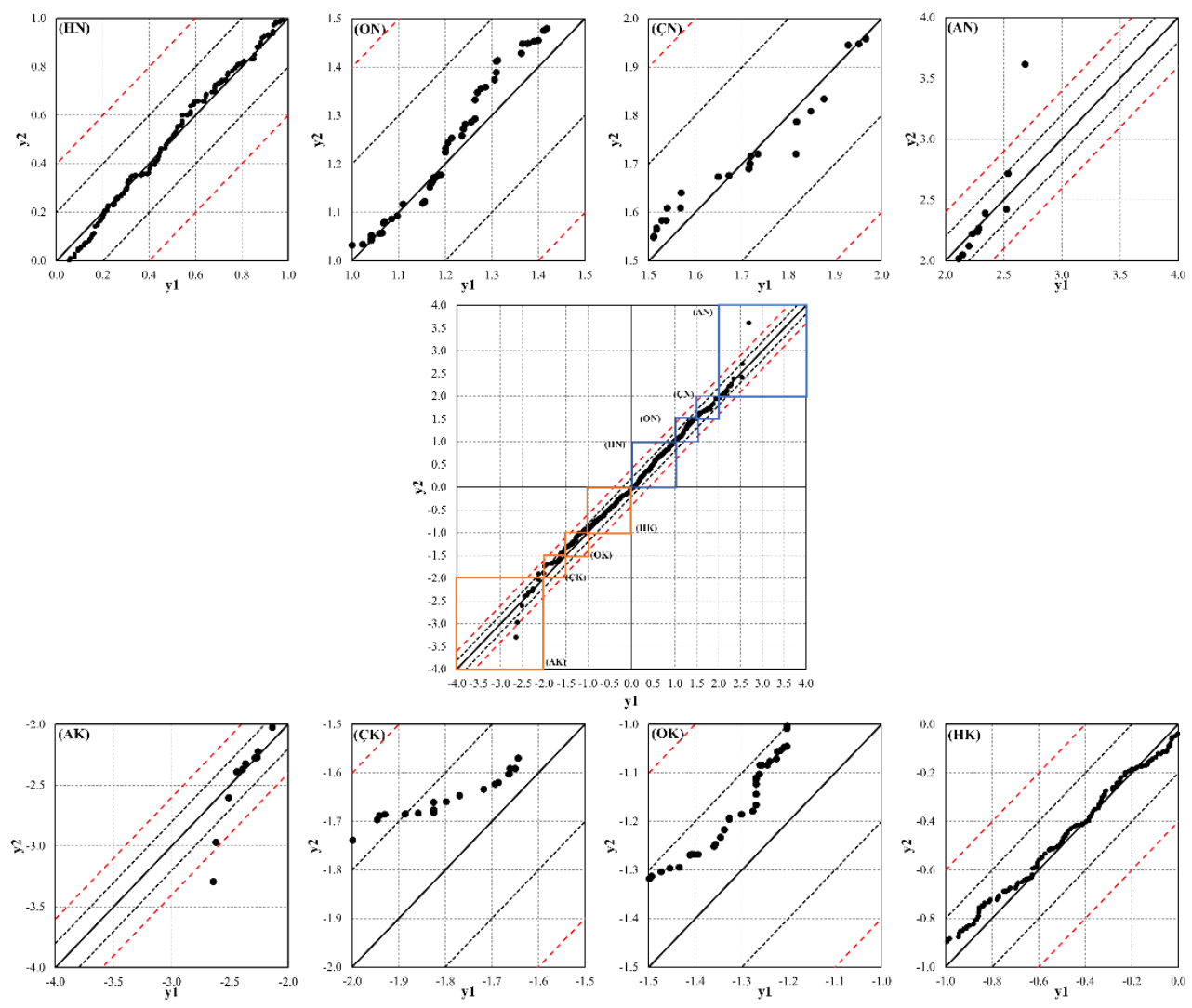

Şekil 7: ITA yöntemine göre SYI-3 değerlerinin değişimleri
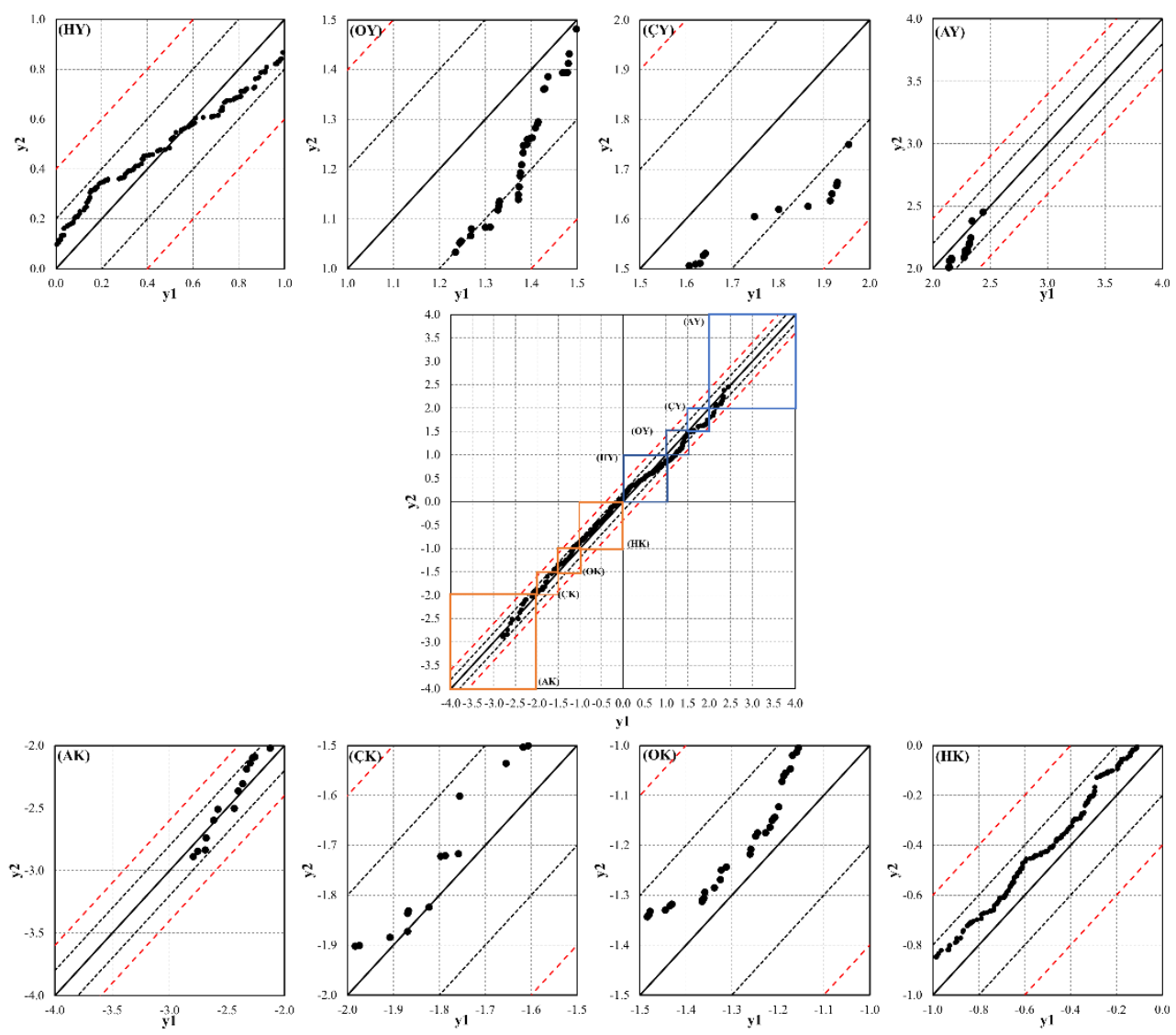

Şekil 8: ITA yöntemine göre SYI 6 değerlerinin değişimleri 

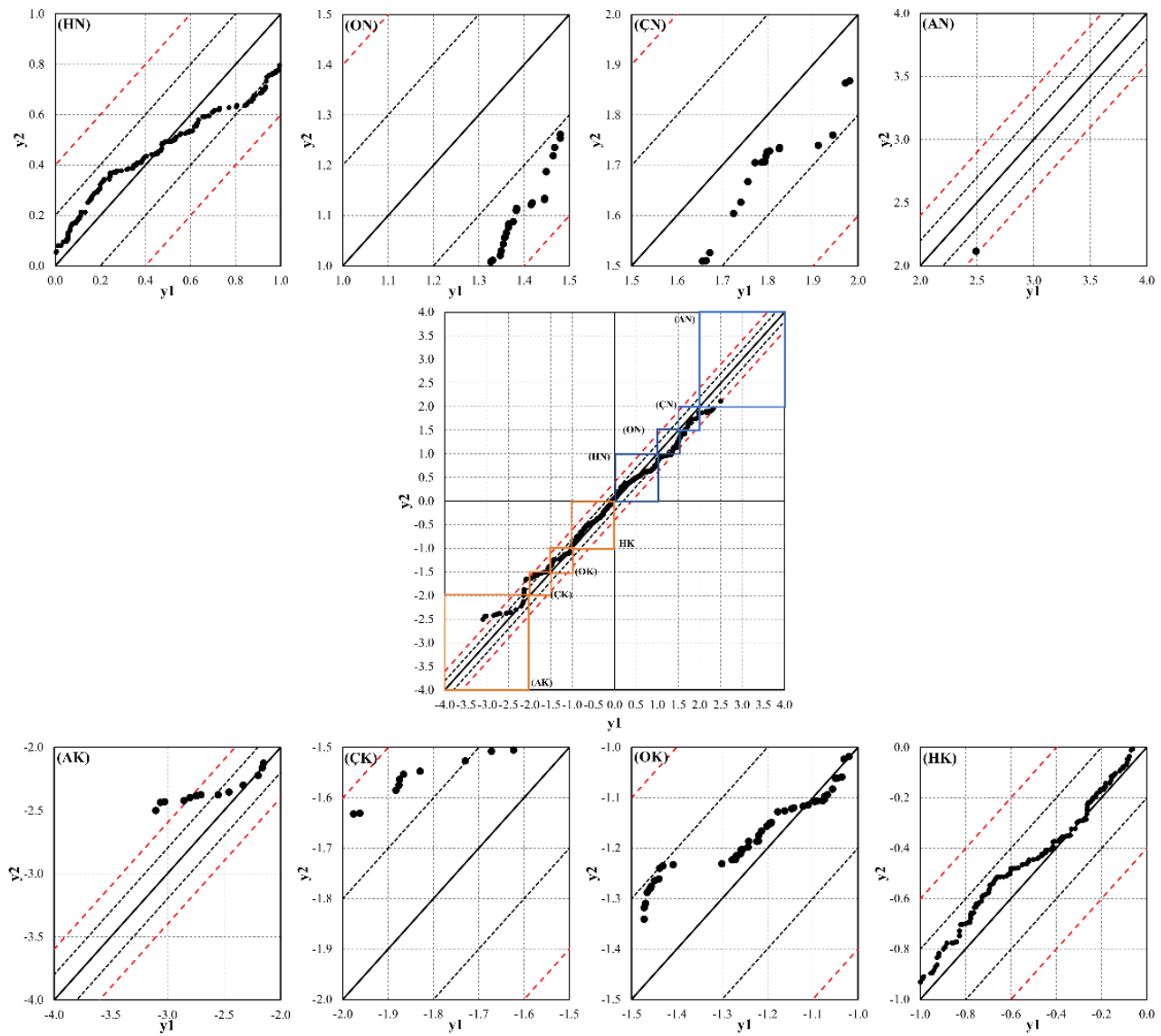

Şekil 9: ITA yöntemine göre SYI 12 değerlerinin değişimleri

\section{Sonuçlar}

Diyarbakır iline ait 1929-2016 yılları arasını kapsayan ölçülmüş aylık toplam yağış verilerinin homojenlikleri kontrol edildikten sonra SYİ yöntemi ile SYI-1, SYI-3, SYI-6 ve SYI-12 olarak aylık kuraklık indis değerleri hesaplanmıştır. Hesaplanan bu indis değerlerinin ITA yöntemi ile her bir kuraklık sınıfı için trendleri belirlenmiş ve aşağıda listelenen sonuçlar elde edilmiştir.

- SYİ-1 için en uzun kurak periyot Eylül 1960’ta başlamış ve 8 ay sürmüş, SYİ-3’te Temmuz 1972 yılında başlamış ve 18 ay sürmüştür. SYİ-6'da 21 ay süren kurak dönem Temmuz 1959'ta, SYİ-12 için ise ölçüm başlangıç tarihi olan Ocak 1929'da başlamış ve 53 ay sürmüştür. Burada elde edilen en önemli sonuç, tüm zaman ölçekleri için son 45 yıl içinde tarihin en yüksek kurak dönemi yaşanmamıştır.

- SYİ indis değerlerinin kurak ve nemli dönem dağılımları ise SYİ-1'de \%60 nemli, \%40 kurak şeklinde olurken, SYİ-3, SYİ-6 ve SYİ-12'de iki dönem de yaklaşık olarak \%50 olmuştur.

- SYİ değerlerinin kuraklık sınıflarına göre meydana gelme yüzdelerinde en yüksek orta kurak (\%10.43) ve aşırı kurak (\%3.25) meydana gelme oranları SYİ-12'de olmuştur. SYİ-3 ve SYİ-6'da ise çok nemli hariç tüm sınıflandırmalarda birbirlerine benzer bir oran çıkmış, orta kurak ve üzeri kurak olma durumu meydana gelme oranı ise $\% 15$ civarında olmuştur.

- SYİ-3’ün ITA sonuçlarından, tüm nemli dönemlerde ve hafif kurak indis değerlerin anlamlı bir değişim olmadığı, orta ve çok kurak indis değerlerinin ise az miktarda artış eğiliminde oldukları görülmüş̧ür. SYİ-6 için yapılan analiz sonucunda sadece aşırı nemli, çok nemli ve orta nemli indis değerlerinde zayıf bir azalma eğilimi gözlenmiş, SYİ-12 değerlerinin ise orta nemli sınıflandırmadaki indis değerlerinde \%5 üzerinden bir azalma eğiliminin olduğu, ancak aşırı kurak sınıfta yer alan -3’ten küçük indis değerlerinin \%10 üzerinde güçlü bir artış eğiliminde olduğu belirlenmiştir.

ITA yönteminin sonuçlarına göre, dört farklı zaman ölçeği ortak değerlendirildiğinde, Diyarbakır istasyonunda kuraklık indis değerlerinin genel olarak değişim göstermediği, ancak özellikle orta ve uzun dönem kuraklıklar (SYİ-3, SYİ-6 ve SYİ12) için aşırı kurak ve çok kurak indislerin hafif de olsa bir artış eğiliminde olduğu, nemli dönemlerde ise yine zayıf bir azalma trendi olmuştur. Böylece, Diyarbakır istasyonunda kuraklığın tarihsel değişimlerinin sınırlı olduğu, sadece negatif indis değerlerinin eğiliminin olumlu yönde olduğu yani kuraklığın azaldığı belirlenmiştir. Görüldüğü üzere, bir zaman serisinde monotonik trend belirlenen yöntemlere göre sadece trend varlığı vermesi dişında, veri setinin 
değişimini daha detaylı analiz etme becerisi ve hesaplama kolaylığı nedeniyle ITA yöntemi oldukça kullanışlı olduğu için, kuraklık şiddetinin değişiminin belirlenmesi için rahatlıkla kullanılabileceği değerlendirilmektedir.

\section{Kaynaklar}

Alexandersson H., Moberg A., (1997), Homogenization of Swedish Temperature Data. Part I: Homogeneity Test for Linear Trends, International Journal of Climatology, 17, 25-34.

Andreadis K.M., Lettenmaier D.P., (2006), Trends in 20th century drought over the continental United States, Geophysical Research Letters, 33, 1-4.

Botterill L.C., (2003), Beyond drought: People, Policy and Perspectives, CSIRO Publishing, 248ss.

Buishand T.A., (1982), Some methods for testing the homogeneity of rainfall records, Journal of Hydrology, 58, 11-27.

Byun H.R., Wilhite D.A., (1999), Objective Quantification of Drought Severity and Duration, Journal of Climate, 12, $2747-2756$.

Caloiero T., (2018), SPI trend analysis of New Zealand applying the ITA technique, Geosciences, 8(3), 101, doi: $10.3390 /$ geosciences8030101.

Cui L., Wang L., Lai Z., Tian Q., Liu W., Li J., (2017), Innovative trend analysis of annual and seasonal air temperature and rainfall in the Yangtze River Basin, China during 1960-2015, Journal of Atmospheric and Solar-Terrestrial Physics, 164, 48-59.

Çiçek İ., Duman N., (2015), Seasonal and annual precipitation trends in Turkey, Carpathian Journal of Earth and Environmental Sciences, 10, 77-84.

Dashtpagerdi M.M., Kousari M.R., Vagharfard H., Ghonchepour D., Hosseini M.E., Ahani H., (2015), An investigation of drought magnitude trend during 1975-2005 in arid and semi-arid regions of Iran, Environmental earth sciences, 73, 1231-1244.

Dikici M., (2020), Drought analysis with different indices for the Asi Basin (Turkey), Scientific Reports, 10, 20739, doi: $10.1038 / \mathrm{s} 41598-020-77827-\mathrm{z}$

Gumus V., Algin H.M., (2017), Meteorological and hydrological drought analysis of the Seyhan-Ceyhan River Basins, Turkey, Meteorological Applications, 24, 62-73.

Gumus V., (2019), Spatio-temporal precipitation and temperature trend analysis of the Seyhan-Ceyhan River Basins, Turkey, Meteorological Applications, 26, 369-384.

Hadi S.J., Tombul M., (2018), Long-term spatiotemporal trend analysis of precipitation and temperature over Turkey, Meteorological Applications, 25, 445-455.

Heim R.R., (2002), A Review of Twentieth-Century Drought Indices Used in the United States, Bulletin of the American Meteorological Society, 83, 1149-1166.

Jamro S., Channa F.N., Dars G.H., Ansari K., Krakauer N.Y., (2020), Exploring the Evolution of Drought Characteristics in Balochistan, Pakistan, Applied Sciences, 10(3), 913, doi: 10.3390/app10030913.

Kendall M.G., (1948), Rank correlation methods. Griffin, London, England.

Keskin M.E., Terzi O., Taylan D., Kucukyaman D., (2011), Meteorological drought analysis using artificial neural networks, Scientific Research and Essays, 6, 4469-4477.

Liu C., Yang C., Yang Q., Wang J., (2021), Spatiotemporal drought analysis by the standardized precipitation index (SPI) and standardized precipitation evapotranspiration index (SPEI) in Sichuan Province, China, Scientific Reports, 11, 1280, doi: 10.1038/s41598-020-80527-3.

Liu D., You J., Xie Q., Huang Y., Tong H., (2018), Spatial and Temporal Characteristics of Drought and Flood in Quanzhou Based on Standardized Precipitation Index (SPI) in Recent 55 Years, Journal of Geoscience and Environment Protection, 06, 25-37.

Liu X., Liu C., Luo Y., Zhang M., Xia J., (2012), Dramatic decrease in streamflow from the headwater source in the central route of China's water diversion project: Climatic variation or human influence?, Journal of Geophysical Research: Atmospheres 117, 110.

Mann H.B., (1945), Nonparametric tests against trend, Econometrica: Journal of the econometric society, 245-259.

Marini G., Fontana N., Mishra A.K., (2018), Investigating drought in Apulia region, Italy using SPI and RDI, Theoretical and Applied Climatology, 137, 383-397.

McKee T.B., Doesken N.J., Kleist J., (1993), The relationship of drought frequency and duration to time scales, Proceedings of the 8th Conference on Applied Climatology, Boston, 179-183.

Mishra A.K., Desai V.R., (2005), Spatial and temporal drought analysis in the Kansabati river basin, India, International Journal of River Basin Management, 3, 31-41

Naz D., Ansari J.K., (2020), Drought Trends in Balochistan, Water, 12(2), 470, doi: doi.org/10.3390/w12020470.

Nazmi D., Aydinsakir K., Mesut I., Buyuktas D., (2016), Standartlaștırılmıs yă̆lş indeksi (SPI) yöntemi ile Antalya ili kuraklık analizi, Derim, 33, 279-298.

Nourani V., Danandeh Mehr A., Azad N., (2018), Trend analysis of hydroclimatological variables in Urmia lake basin using hybrid wavelet Mann-Kendall and Şen tests, Environmental Earth Sciences, 77, 207, doi: 10.1007/s12665-018-7390-x.

Nyatuame M., Agodzo S., (2017), Analysis of Extreme Rainfall Events (Drought and Flood) over Tordzie Watershed in the Volta Region of Ghana, Journal of Geoscience and Environment Protection, 05, 275-295.

Omonijo T.O., Okogbue E.C., (2014), Trend Analysis of Drought in the Guinea and Sudano-Sahelian Climatic Zones of Northern Nigeria (1907-2006), Atmospheric and Climate Sciences, 04, 483-507.

Palmer W.C., (1965), Meteorological drought, US Department of Commerce, Weather Bureau.

Pettitt A.N., (1979), A Non-Parametric Approach to the Change-Point Problem, Journal of the Royal Statistical Society. Series C (Applied Statistics), 28(2), 126-135.

Sharafati A., Nabaei S., Shahid S., (2020), Spatial assessment of meteorological drought features over different climate regions in Iran, International Journal of Climatology, 40, 1864-1884.

Şen Z., (2012), Innovative Trend Analysis Methodology, Journal of Hydrologic Engineering, 17, 1042-1046. 
Tosunoglu F., Kisi O., (2017), Trend Analysis of Maximum Hydrologic Drought Variables Using Mann-Kendall and Şen's Innovative Trend Method, River Research and Applications, 33, 597-610.

Vermes L., (1998), How to work out a drought mitigation strategy, An ICID Guide. Guidelines for Water Management. Bonn. DVWK 309, 29.

Vicente-Serrano S.M. vd., (2020), Long-term variability and trends in meteorological droughts in Western Europe (1851-2018), International Journal of Climatology, 41(S1), 690-717.

Wilhite D.A., (2000), Drought as a natural hazard: concepts and definitions, in: Wilhite, D.A. (Ed.), Drought: A Global Assessment, Routledge, ss. 3-18.

Wilhite D.A., Glantz M.H., (1985), Understanding: the Drought Phenomenon: The Role of Definitions, Water International, 10, 111120. 